\title{
Aristotle on Nonsubstantial Individuals
}

\author{
Phil Corkum
}

As a first stab, call a property recurrent if it can be possessed by more than one object, and nonrecurrent if it can be possessed by at most one object. The question whether Aristotle holds that there are nonrecurrent properties has spawned a lively and ongoing debate among commentators over the last forty-five years. One source of textual evidence in the Categories, drawn on in this debate, is Aristotle's claim that certain properties are inseparable from what they are in. Here the point of contention is whether this commits Aristotle to holding that these properties are inseparable from individuals, since it is commonly held that a property is nonrecurrent, if it is inseparable from an individual. I argue that this evidence is neutral on the question whether there are nonrecurrent properties in Aristotle. One of my aims here is to disentangle the question of recurrence from local issues of individuality and universality in the Categories. But another aim is to turn from the textual considerations, which have dominated the debate, to broader methodological considerations. It is a shared assumption among all those who look to textual evidence from the Categories, so to decide whether Aristotle believes there are nonrecurrent properties, that in this work Aristotle is engaged in a project where the question of recurrence is relevant. I argue that Aristotle's concerns in the Categories are disjoint from the question of recurrence, and so this shared assumption is false.

\section{The Philosophical Issue}

In the Categories, Aristotle classifies beings into individual and universal substances, and also individuals and universals in categories other than substance, such as quality and quantity. I call these kinds of beings 'nonsubstances'. The basis of this classification is two kinds of predication: a thing may be said of a subject and a thing may be present in a subject. Individual substances such as Callias are neither said of, nor present in, a subject; universal substances such as human are said of, but not present in, a subject; nonsubstantial universals such as colour are both said of, and present in, a subject; and nonsubstantial individuals are present in, but not said of, a subject. ${ }^{1}$ What sort of things are nonsubstantial individuals? Aristotle's examples are a 'certain case of grammatical knowledge' (hê tis grammatikê) present in a soul and a 'certain paleness' (to ti leukon) pre-

${ }^{1}$ I refer to such notions as inherence and also to the two-place expressions themselves referring to these notions, as ties and not relations so to avoid confusion between these syncategorematic notions and expressions and the Aristotelian category of relation. For the usage and its motivation, see Strawson 1959, 167. 
sent in a body. But it is not clear from these examples whether your soul and mine share the same certain item of grammatical knowledge. Or whether your body and mine can share the same paleness.

Before turning to the interpretative question of which view, the view that nonsubstantial individuals are recurrent or the view that they are nonrecurrent, we ought to ascribe to Aristotle, I shall unpack the underlying philosophical issue. One finds surprisingly little discussion in the secondary literature of what is of philosophical interest in the debate, and it will pay dividends later to spell out here, even in a somewhat sketchy and schematic way, the opposed positions in the metaphysics of properties that underlie the issue. I begin by considering the notion of recurrence itself. In an early formulation, Owen 1965, 99 glosses recurrence as a capacity for being found in more than one subject. This formulation arguably serves to get the reader on to the basic issue, but its imprecision is a handicap. The question at hand is whether a property can be possessed by more than one object or, in terms closer to Aristotle's terminology, whether a predicable can be predicated of more than one individual substance. So Owen's formulation is potentially misleading: a nonrecurrent item could be predicated of more than one subject, provided it is not predicated of more than one individual substance. Indeed, this is often the case; even if a given nonsubstantial individual is predicated of at most one individual substance, it is often true that that very individual is also predicated of several subjects. For example, if nonsubstantial individuals are nonrecurrent, then Callias' colour can be predicated of only one individual substance, Callias. Nonetheless, Callias' colour may be predicated also of Callias' skin or Callias' body. In fact, Aristotle seems to go out of his way to bring this to his reader's attention: his examples of subjects include bodies, which are not substances.

In one of the few detailed formulations of recurrence in the secondary literature, Wheeler 1999, 543 views recurrence not as a feature of properties found in different subjects but as a feature of existents over different places or times, writing that an existent is recurrent if it either exists '(a) at numerically different places at numerically the same time or (b) at numerically different times connected by no closed interval during all of which [the item] exists'. I believe that this formulation misses what is of importance in the issue. The question of recurrence is not an issue of the synchronic or diachronic existence of properties so much as one of property individuation. The issue is then whether there are cases where what it is to be a given property involves possession by some specific object or, again in Aristotle's terminology, whether what it is to be a given nonsubstantial individual is for there to be some specific individual substance that is the sole individual substance of which the nonsubstantial individual is predicated. A property may be so individuated yet arguably fail either of Wheeler's conditions. My skin colour exists in several places simultaneously, being on the surface of both of my two feet. Yet one might hold that my skin colour is a property individuated by myself alone, and so an item may be nonrecurrent yet exist at numerically different places at numerically the same time. One might also hold 
that a nonrecurrent item could exist at numerically different times separated by a time during which the item does not exist. Since substances are of course persistent, a single property may inhere in the same substance at two distinct times, with some interval of time between during which the substance lacks the property, yet the property still be the same nonsubstantial individual. So it may be that Callias' paleness is the same nonrecurrent property from one winter to another, yet be different from an indistinguishable shade inherent in Socrates. For these reasons, the term 'recurrence' is unfortunate: an item may be designated 'nonrecurrent' in the sense relevant to the issue yet periodically occur in the sense just explained. Since the terminology is now standard in the literature, I continue to use it. However, we need to keep in mind that, under the relevant notion of recurrence, a nonsubstantial individual is recurrent if it can be present in more than one individual substance and nonrecurrent if it can be present in at most one individual substance.

I now turn to the contrast between the two positions on the issue whether there are nonrecurrent properties. One finds occasionally the view expressed that one position or the other is absurd. For example, complaining against the 'dogma' that nonsubstantial individuals are nonrecurrent, Owen 1965, 102 writes: 'it is when the dogma is extended to other categories [other than the category of quality] that it becomes a joke: so that two things cannot be said to have the same particular size when they are both six feet tall, or cannot be said to occupy the same particular place at different times'. However, the view that nonsubstantial individuals are nonrecurrent is not the absurd view that two things cannot both be six feet tall. The advocate of nonrecurrent individuals may hold that even the property of being a specific height, such as the property of being exactly six feet tall, is a universal capable of being possessed by more than one individual substance, while maintaining that each individual property of being six feet tall is a distinct property that, being individuated by its sole possessor, cannot be possessed by more than one individual substance. For the view that nonsubstantial individuals are nonrecurrent is the position that, when two individuals resemble each other in some respect or share the same universal property, no matter how fine-grained, they do so in virtue of possessing two distinct properties. These properties may both fall under the same relevant nonsubstantial universal, but each is individuated by the distinct individual substance that possesses it. Consider the alleged example of an individual colour such as my paleness. On this view, my paleness is properly described as mine and so cannot be found in any other subject. As a result, nonsubstantial individuals are nonrecurrent and the contrast between nonsubstantial individuals and nonsubstantial universals is between items that are nonrecurrent and items that are recurrent or common to more than one substance. $^{2}$

${ }^{2}$ For similar responses to Owen's dismissal of the view that nonsubstantial individuals are nonrecurrent, see Allen 1969, 34-35 n6) and Wedin 1993, 139. Another reason for thinking that Aristotle should not be saddled with the view that nonsubstantial individuals are nonrecurrent is that Aristotle also holds that there are universals. Typically, theorists advocate tropes or nonrecurrent properties as 
Others have found the position that nonsubstantial individuals are recurrent worthy of dismissal. You and I may share the exact same kind of colour but of course you may not possess the particular instance of that colour that is mine. So, as some have said to me in personal correspondence, to assert that nonsubstantial individuals are recurrent is either the banal observation that two instances may share the same kind of colour or the absurd claim that two things may possess the exact same instance of a colour. However, the view that nonsubstantial individuals are recurrent is the position that two nonsubstantial individuals, which fall under the same nonsubstantial universal, are not necessarily numerically distinct properties. The advocate of the view that nonsubstantial individuals are recurrent would deny that properties are shared in virtue of two individuals possessing distinct properties that, although both falling under the same relevant nonsubstantial universal, are each individuated by their own distinct individual substance. Rather, they would say that properties are necessarily items that may be possessed by more than one individual substance. When two individual substances resemble each other in some respect, they do so in virtue of sharing a numerically identical property. A nonsubstantial individual can not be individuated by the sole individual substance in which it is present, since it can in principle be present in more than one individual substance. On this view, nonsubstantial individuals are not distinct properties individuated by individual substances but are properties not predicable of any less general property. As such, nonsubstantial individuals are least general properties that may be shared by several individual substances and so are in principle recurrent. The contrast between nonsubstantial universals and nonsubstantial individuals, then, is not on this view the contrast between nonrecurrent and recurrent items but is rather the contrast between properties expressed by terms that are predicable of less general properties and those expressed by terms that are not predicable of less general properties. Individual colours, for example, are on this view not instances such as my particular paleness but are rather fine-grained hues, colour types that cannot be further divided into species. Owen's own example is a species of pink, for which Owen coins the term, 'vink'. You and I may share vink, but we cannot intelligibly further divide this colour type into, say, lighter vink and darker vink.

The debate between those who hold that some properties are nonrecurrent and those who hold that all properties are recurrent is then a genuine disagreement. With this sketch of the philosophical issue and the two opposed positions in the background, I turn now to the question of which view, the view that nonsubstantial individuals are recurrent or the view that they are nonrecurrent, we ought to ascribe to Aristotle. I begin by considering the textual evidence in the Categories before turning, in the last section, to broader methodological considerations. My

an alternative to explaining attribute agreement by appeal to universals. However, a trope theorist need not view universals as redundant. For contemporary trope theory and the coinage of the term, 'trope', in this context, see Williams 1953. For the charge that universals are redundant for the trope theorist, see Armstrong 1989, 132. For defenses of the view that there are both tropes and universals, see Cook Wilson 1926 and Mertz 1996. 
aim is first to demonstrate that the textual evidence is neutral on the question of recurrence and then to propose an explanation of this neutrality.

\section{Textual Evidence}

Nonsubstantial individuals are inherent or present in a subject, and much of the debate on the issue of recurrence has centered on the apparent definition of inherence at Categories 1a24-25: 'By "in a subject" I mean (legô) what is in something (tini), not as a part, and cannot exist separately (adunaton chôris einai) from what it is in (tou en hôi estin).' As I show in more detail below, the assumption that a property is nonrecurrent if it is inseparable from an individual subject drives much of the dialectic of the debated reading of 1a24-25. Those who hold that nonsubstantial individuals are nonrecurrent properties read 1a24-25 as claiming that any nonsubstantial individual is inseparable from its subject, an individual substance; and those who hold that nonsubstantial individuals are recurrent read 1a24-25 as only committed to the claim that nonsubstantial individuals are inseparable from some of the subjects in which they are found, but not from the individual substances in which they are found.

Although the view that nonsubstantial individuals are nonrecurrent properties was arguably something of an orthodoxy in the $20^{\text {th }}$ century before 1965 , Ackrill 1963, 74-75 in reading 1a24-5 provides a more or less explicit argument for the view. ${ }^{3} \mathrm{He}$ interprets the passage as giving the following necessary and sufficient condition for inherence:

(A) $\mathrm{x}$ is present in $\mathrm{y}$ just in case:

(i) $\mathrm{x}$ is in $\mathrm{y}$

(ii) $\mathrm{x}$ is not a part of $\mathrm{y}$

(iii) $\mathrm{x}$ cannot exist independently from $\mathrm{y} .{ }^{4}$

As Ackrill 1963, 74 notes, (A) is circular unless we distinguish the 'in' in the definiendum from the 'in' in the definiens. Ackrill suggests that (A, i) employs a non-technical notion of being in, writing that "Aristotle has in mind the occurrence in ordinary Greek of locutions like "heat in the water", "courage in Socrates".' So, on Ackrill's reading of 1a24-25, inhering in something is a special way of being in that thing, namely, being neither a part of that thing nor capable of existing independently from that thing. Following Ackrill, I call this special way of being in something being present in that thing.

Ackrill takes (A) to entail that nonsubstantial universals can not be present in individual substances. He writes: 'Aristotle could not say that generosity is [present] in Callias as subject, since there could be generosity without any Callias. Only this individual generosity -Callias' generosity - is [present] in Callias' $(1963,74)$. Let us track the moves here more carefully. There is a tacit assumption in Ackrill's argument, namely:

(A1) If $\mathrm{x}$ cannot exist independently from an individual subject, then $\mathrm{x}$ is non-

\footnotetext{
${ }^{3}$ For evidence of the orthodoxy of this view, see Owen (1965: 97).

${ }^{4}$ For the reader's convenience, I have listed the labeled sentences at the end of the article.
} 
recurrent.

Condition (A, iii) has the following consequence when conjoined with (A1):

(A2) Only nonrecurrent properties can be present in individual substances.

I take the expressions 'cannot exist independently', 'cannot exist separately', 'cannot exist apart', and so on as synonyms. (A2) entails, when conjoined with the uncontroversial thesis that nonsubstantial universals are recurrent properties, the claim that nonsubstantial universals can not be present in individual substances. This is what Ackrill asserts in the above quotation. This, then, is Ackrill's argument for the claim that nonsubstantial individuals are nonrecurrent properties: (A) is the correct reading of 1a24-25; (A) entails (A2) under the plausible assumption of (A1); nonsubstantial individuals are present in individual substances; so nonsubstantial individuals are nonrecurrent properties.

(A2) is open to the objection that 2a34-b7 seems explicitly to deny the claim:

All the other things are either said of the primary [i.e., individual] substances as subjects or in them as subjects... [C]olour is in body and therefore also in an individual body; for were it not in some individual body it would not be in body at all... So if the primary substances did not exist it would be impossible for any of the other things to exist.

This passage seems to say that nonsubstantial universals are present in individual substances. This entails the denial of (A2) when conjoined with the uncontroversial thesis that universal properties are recurrent. Ackrill 1963, 83 denies that the passage does have this entailment, writing that:

to say that colour is in body is to say that every instance of colour is in an individual body. If so, Aristotle's present formulation is compressed and careless. For he does not mention individual instances of colour; he speaks as if, because colour is in body, colour is in an individual body. Strictly, however, it is not colour, but this individual instance of colour, that is in this individual body; for colour could exist apart from this body (though this instance of colour could not). Aristotle's use of a relaxed sense of 'in' may be connected with his almost complete neglect, after [Categories] Chapter 2, of individuals in non-substance categories.

Subsequent interpreters have ascribed to Aristotle not carelessness but a distinct and derivative sense of being in a subject. To keep things clear, let us disambiguate the senses of being in by subscription and call the non-technical sense of being in a subject, which Ackrill claims occurs in the definiens of 1a24-25, 'in 1 ', and the notion of being present in a subject, occurring in the definiendum of 1a24-25, 'in 2 '. Moravcsik 1967, 87 writes that 'general attributes are indirectly inherent in particular substances'. Allen 1969, 35 takes a similar line, writing: "the "in" here [in 2a34-b7] is not the technical "in" of presence [i.e., in 2 ], but an "in" derived from it...in that the first must obtain if the second is assertible'. Allen thus takes it that there is a third sense of 'in' in the Categories in addition 
to the 'in' of the definiendum of 1a24-25 and the occurrences of 'in' in the definiens: call this notion being in $_{3}$. Allen's reading has the advantage over Ackrill's of not ascribing carelessness to Aristotle. Rather, Allen has a precise condition for a universal $x$ to be $i_{3} y$ : just in case an instance of $x$ is $i_{2} y$. Others have gone further. Duerlinger 1970, 185-186 explains 2b2-4 by successive applications of two accounts of derivative inherence. Let us say that $\mathrm{A}$ is $\operatorname{in}_{4} \mathrm{~B}$ iff $\mathrm{A}$ is predicated of $a$ and $a$ is $\operatorname{in}_{2} \mathrm{~B}$; and that $\mathrm{A}$ is $\operatorname{in}_{5} \mathrm{~B}$ iff, for some $\mathrm{x}$ and some $\mathrm{y}, \mathrm{A}$ is predicated of $\mathrm{x}$ and $\mathrm{B}$ is predicated of $\mathrm{y}$, and $\mathrm{x}$ is $\operatorname{in}_{2} \mathrm{y}$. Then colour is $\mathrm{in}_{5}$ body since colour is predicated of a particular colour and body is predicated of a particular body, and the particular colour is $\mathrm{in}_{2}$ the particular body. Then, by the definition of being $\mathrm{in}_{4}$, colour is $\mathrm{in}_{4}$ the particular body.

Some have been persuaded by this line of response to the objection to (A2, see, e.g., Heinaman 1981, 303). But it is an unattractive reading of 2a34-b7. For one thing, it requires positing at least a third sense of 'in', a postulation without independent textual support. But worse, as Frede 1987, 89 notes, the reading renders 2a34-b7 invalid. For if the sense in which the nonsubstantial universal colour is in individual substances were not the sense in which things are claimed at $2 \mathrm{a} 35$ to be in the primary substances as subjects, then the claim that colour is in individual substances would provide no evidence for the claim that all the other things are either said of the primary substances as subjects or in them as subjects. Indeed, 2a34-b7 is entirely mysterious on this reading. If the argument is to be valid, then each occurrence of 'in' must express the same notion of being in; since the first sentence requires that 'in' expresses the notion of being present in, each occurrence of 'in' must express the notion of being present in.

Partly because of this objection to (A2) and other objections, ${ }^{5}$ Owen 1965 rejects both (A) and Ackrill's thesis that nonsubstantial individuals are nonrecurrent properties. Recall, on Ackrill's view, nonsubstantial individuals are instances of properties that are individuated by the individual substances in which they inhere. Consider again the example of an individual colour such as my paleness. On Ackrill's view, my paleness is properly described as mine and so cannot be found in any other subject. As a result, nonsubstantial individuals are nonrecurrent. On this view, the contrast between nonsubstantial individuals and nonsubstantial universals is between items that are nonrecurrent and items that are recurrent or common to more than one subject. On Owen's view, by con-

5 Owen's three other objections have been adequately met by Allen 1969 and other authors. First, Owen 1965, 101 argues that (A) makes all nonsubstances relative. Allen 1969, 33-34 rightly responds that (A) only makes all non-substances dependent, a syncategorematic notion, not relative, a categorical notion. Secondly, Owen 1965, 101 argues that (A) entails a 'paradox of implication': since it is not pink, say, which is in Socrates but Socrates's pink, 'The colour in Socrates's body is pink' is ill-formed. Allen 1969, 34 responds that 'The colour in Socrates's body is Socrates's pink' is an identity statement; 'The colour in Socrates's body is pink' is a well-formed, true predicative statement. Moravcsik 1967, 87 responds similarly. Thirdly, Owen 1965, 102 claims that (A) precludes asserting that two things have the same particular size. Allen 1969, 34n6 responds that " a particular size" is ambiguous as between a particular instance of size (which no two things can share) and a particular species of size (which many things can share)'. 
trast, nonsubstantial individuals are not instances individuated by individual substances but are properties not predicable of any less general property. As such, nonsubstantial individuals are the least general properties that may be shared by several individual substances and so are in principle recurrent. Individual colours, for example, are on this view not instances such as my particular paleness but are rather fine-grained hues, colour types that cannot be further divided into species. Since nonsubstantial individuals are on this view not nonrecurrent properties but may exist in more than one subject, Owen cannot interpret 1a24-25 as (A); he rather offers the following:

(B) $\mathrm{x}$ is present in $\mathrm{y}$ just in case: there is a $\mathrm{z}$ such that

(i) $\mathrm{x}$ is in $\mathrm{y}$

(ii) $x$ is not a part of $y$

(iii) $\mathrm{x}$ cannot exist apart from $\mathrm{z}$.

Owen's reading shares some of the features of Ackrill's reading: both take inherence to be a special way of being in something, a way different from the way in which a part is in a thing. But Ackrill's reading has the consequence that an inherent item cannot exist independently from that in which it inheres. Owen's reading does not have this consequence; rather, Owen's reading has merely the much weaker consequence that an inherent item cannot exist independently from something or other. On Owen's view, an individual colour is a least general property such as vink that, recall, is Owen's coined term for a specific shade of pink. A plausible candidate for an item apart from which vink cannot exist is the universal body. There are no bodiless colours. So vink, let us say, inheres in me and this is in part because it cannot exist apart from body, of which my body is an instance. But vink can also inhere in you, since the requirement is merely that vink cannot exist apart from body, and your body is also an instance of body. On Owen's reading, you and I could share an inherent property, since although the item inheres in me, it is not incapable for existing apart from me; indeed, it can exist apart from me, by also inhering in you. As a result, (B) does not entail (A2), the claim that only nonrecurrent properties can inhere in individual substances.

However, as Heinaman 1981, 296 and others note, (B) is an unattractive reading of 1a24-25. Consider again the passage: "By "in a subject" I mean (legô) what is in something (tini), not as a part, and cannot exist separately (adunaton chôris einai) from what it is in (tou en hôi estin).' Owen's reading, (B), requires that the indefinite pronoun tini and the relative clause tou en hôi estin in 1a24-25 have different referents: their referents are represented in (B) as the variables ' $y$ ' and ' $z$ ' respectively. Yet the close proximity of tini and tou en hôi estin strongly suggests that they have the same referent or, at least, that they do not refer to two different specific referents. (B) thus forces an arguably unnatural reading of 1a24-25.

So the considerations of this section have yielded two desiderata. We would like to hold that all occurrences of 'in' in 2a34-b7 express the notion of inherence. The interpretation offered by Ackrill and his supporters fails to meet this desideratum. And we would like to hold that tini and tou en hôi estin in 1a24-5 
have the same referent. The interpretation offered by Owen and his supporters fails to meet this desideratum. ${ }^{6}$ Notice that one assumption held in common by the participants in the debate is the thesis I have labeled (A1), the plausible claim that an item is nonrecurrent if it is inseparable from an individual substance. It is this assumption, when conjoined with the claim that tini and tou en hô $i$ estin in 1a24-25 have the same referent, that leads to the undesirable consequence, (A2), the claim that only nonsubstantial individuals are present in individual substances. (A2) conflicts with 2a34-b7, so Ackrill and his supporters, having retained both assumptions, have been forced into an unnatural reading of 2a34b7. Owen and his supporters, on the other hand, have also held the assumption that an item is nonrecurrent if it is inseparable from an individual substance and, preferring the natural reading of $2 \mathrm{a} 34-\mathrm{b} 7$, have been forced to drop the claim that tini and tou en hôi estin in 1a24-25 have the same referent. An interpretation meeting both of our desiderata while retaining the plausible claim that claim that an item is nonrecurrent if it is inseparable from an individual substance would, all else being equal, be preferable to either the Ackrill or the Owen interpretation.

\section{Other Interpretations}

Before offering my interpretation, I discuss two more recent readings of 1a2425 , one of which supports the view that nonsubstantial individuals are recurrent and other of which supports that they are nonrecurrent. These interpretations fall somewhat outside the dialectic presented in the previous section, and the impatient reader could skip this section.

Wedin 1993 defends the view that nonsubstantial individuals are nonrecurrent with a reading of 1a24-25 that does not entail (A2) and so does not have the result that no nonsubstantial universal can be present in an individual. Wedin's reading, then, does not run afoul of the natural reading of 2a34-b7, under which nonsubstantial universals inhere in individual substances. So one could take Wedin's reading and not be forced to reject the assumption that an item is nonrecurrent if it is inseparable from an individual substance. Wedin 1993, 151 reads 1a24-25 along the lines of the reading typically favored by those who hold that nonsubstantial individuals are recurrent:

$\mathrm{x}$ is in something, $\mathrm{z}$, as its subject iff there is a subject $\mathrm{y}$ such that

(i) $x$ is in $y$

(ii) $\mathrm{x}$ is not a part of $\mathrm{y}$

(iii) $x$ cannot exist apart from $y$.

This reading, of course, allows the view that nonsubstantial individuals are recurrent. Indeed, as we have seen, this was Owen's motivation for broaching this line of reading of 1a24-25. Wedin blocks the view that nonsubstantial individuals are

${ }^{6}$ Supporters of the view that nonsubstantial individuals are nonrecurrent properties include Ackrill 1963, Allen 1969, Duerlinger 1970, Devereux 1992, Wedin 1993, and Wheeler 1999. Supporters of the view that nonsubstantial individuals are recurrent properties include Owen 1965, Dancy 1975, Heinaman 1981, Hetherinton 1984, Gill 1984, Furth 1988, Matthews 1989 and 1991, Frede 1989, and Erginel 2004. 
recurrent by restricting the above reading with the following condition:

If $\mathrm{y}=\mathrm{z}$ then either

$\mathrm{x}$ is an individual iff $\mathrm{y}$ is an individual; or

$\mathrm{x}$ is a universal iff $\mathrm{y}$ is a universal.

So putting these together, we have the proposal

(C) $\mathrm{x}$ is in something, $\mathrm{z}$, as its subject iff there is a subject $\mathrm{y}$ such that

(i) $\mathrm{x}$ is in $\mathrm{y}$

(ii) $\mathrm{x}$ is not a part of $\mathrm{y}$

(iii) $\mathrm{x}$ cannot exist apart from $\mathrm{y}$.

(iv) if $y=z$ then either: $x$ is an individual iff $y$ is an individual; or $\mathrm{x}$ is a universal iff $\mathrm{y}$ is a universal.

(C) does not require that no nonsubstantial universal is in an individual. A nonsubstantial universal such as colour (corresponding to the substituend for ' $x$ ') is present in a body (the substituend for ' $z$ ') because it is in body, a universal (the substituend for ' $y$ '), not as a part and is inseparable from body. As such, the situation where the substituends for ' $y$ ' and ' $z$ ' are coreferential does not arise for this case. However, the addition of the condition $(C$, iv) ensures that, should the ' $y$ ' and ' $z$ ' terms co-refer, the inherent property is inseparable only from something of the same level of generality. So a nonsubstantial individual is inseparable only from an individual. Under the assumption held in common by all participants in the debate, the claim that I have labeled (A1), this entails that the nonsubstantial individual is nonrecurrent.

In this way, Wedin offers a sophisticated nonrecurrence reading of 1a24-25. However, Wedin's view has its own problems. First, (C) runs afoul of the problem plaguing (B): it requires that we reject the natural reading of $1 \mathrm{a} 24-25$ by holding that tini and tou en hôi estin refer to two different specified referents. Second, Wedin requires the condition $(\mathrm{C}$, iv) to exclude using his own interpretation of 1a24-25 in a way that would be friendly to the view that nonsubstantial individuals are recurrent. Some of the others who ascribe to Aristotle the view that nonsubstantial individuals are nonrecurrent, we have seen, hold that there are several senses of 'in' in 2a34-b7, so that the sense in which a nonsubstantial individual is in an individual substance is not the sense in which a nonsubstantial universal is in an individual substance. Wedin need not take this unattractive reading of 2a34-b7. Rather, he imposes a restriction on a unitary notion of being present in a subject so to preclude nonsubstantial universals from being incapable of existing apart from individual substances. However, as Erginel 2004, 202n55 notes, an independent motivation for ascribing $(\mathrm{C}$, iv) to Aristotle is hard to come by. If there were good textual evidence supporting this ascription, Wedin's interpretation would provide, I believe, the best support for those who would read 1a24-25 and related passages as supporting the view that there are nonrecurrent properties in Aristotle. But I do not know of any good textual evidence supporting the ascription of $(\mathrm{C}$, iv) to Aristotle.

I turn to the second of the two interpretations I discuss in this section. Frede 1987,62 offers a reading of $1 \mathrm{a} 24-25$ that is consistent with the view that nonsub- 
stantial individuals are recurrent. He views the passage as committed only to the following:

(D) $\mathrm{x}$ is present in something as its subject if there is a subject $\mathrm{z}$ such that

(i) $\mathrm{x}$ is not a part of $\mathrm{z}$

(ii) $\mathrm{x}$ cannot exist independently from $\mathrm{z}$.

Notice, (D) preserves the assumption, held in common by supporters of (A), (B), and (C), which I have labeled (A1), the claim that an item is nonrecurrent, if it is inseparable from an individual substance. The strategy of (D), like (B), is to claim that it is not an individual substance from which the inherent property is inseparable. However, an advantage that (D) offers over (B) is that (D) avoids claiming that tini and tou en hôi estin in 1a24-25 have different specified referents. This move, recall, allowed Owen to hold tacitly the assumption that an item is nonrecurrent, if it is inseparable from an individual substance, while denying that a nonsubstantial individual is nonrecurrent. On Owen's reading, a nonsubstantial individual is present in an individual substance but this only entails that it is inseparable from some subject; it does not entail the stronger claim that the nonsubstantial individual is inseparable from the individual substance in which it is present. However, holding that tini and tou en hôi estin in 1a24-25 have different specified referents is an unnatural reading of the Greek. (D) sidesteps this problem by leaving tini unspecified. So, according to (D), tini denotes a class of subjects in which the inherent item is present, while tou en hôi estin picks out that member of this class of which the item is not a part and from which the item cannot exist. For example, when an individual colour is present in Callias as its subject, it is also present in other things-Callias's body and the universal body of which Callias's body is one instance. According to (D), for an individual nonsubstance such as this colour to be in Callias only requires that the nonsubstance be inseparable from some entity - for example, from the universal body. Part of the appeal of (D) is that, like (B), 1a24-25 has only this weak and uncontroversial commitment. However, unlike (B), (D) does not require us to take the unnatural reading of 1a24-25 that tini and tou en hôi estin in 1a24-25 have different specified referents. Rather, we take tini to be unspecified and this is an arguably more natural reading of 1a24-25. So (D) has many of the advantages of (B) yet is free of some of its disadvantages.

Despite the ingenuity of Frede's proposal, some have offered reasons to reject it as a reading of 1a24-25. For example, Wedin 1993, 142-146 claims that (D) has the consequence that Socrates is present in the unmoved mover. It would be better to say that (D) has the consequence that Socrates is present in a subject. For Socrates is not a part of the unmoved mover and the situation, where Socrates exists and the unmoved does not exist, is impossible. So the condition is met that, according to (D), is sufficient for Socrates to be present in a subject. The subject in which Socrates is present need not be the unmoved mover. However, this is a compelling objection to (D) for, as we have seen, Aristotle denies that any individual substance is present in a subject. Notice that Frede, like Owen, reads 1a2425 as not committed to the claim that a nonsubstantial individual is inseparable 
from the very individual substance in which it is present. Underlying this reading is the assumption that I have labeled (A1), the view that an item is nonrecurrent, if it is inseparable from an individual substance. Although (D) is not vulnerable to the problems of (B), it is vulnerable to Wedin's objection in part because of the way in which (D) reads 1a24-25 as being consistent with (A1).

So to conclude this section, Wedin's interpretation, although flawed, provides the best reading of these passages for those who would read 1a24-25 and related passages as endorsing the view that there are nonrecurrent properties in Aristotle. And Frede's interpretation, although also flawed, provides the best support, of the accounts at which we have looked, for those who would read 1a24-25 and related passages as endorsing the view that there are only recurrent properties in Aristotle. However, an alternative reading that meets both of our desiderata, the desideratum that the two expression tini and tou en hoi estin in 1a24-25 do not refer to two different specified referents and the desideratum that all occurrences of 'in' in 2a34-b7 designate a unitary notion of inherence, and that also avoids the shortcomings of Wedin's and Frede's interpretations, would be preferable.

\section{An Alternative Reading of 1a24-25}

As we have seen, the thesis I have labeled (A1), the plausible claim that an item is nonrecurrent if it is inseparable from an individual substance, is held in common by all contributors to the debate. But the tendency in the secondary literature has been either to hold that a nonsubstantial individual is inseparable from the very individual substance in which it is present or to seek things other than individual substances to be the subjects from which nonsubstantial individuals are inseparable. These are not the only options consistent with the thesis (A1) and I next offer an alternative reading of 1a24-25. I agree with Owen and others that 1a24-25 does not commit Aristotle to the view that nonsubstantial individuals are nonrecurrent. But I do not hold this because I believe that the passage should be read as merely claiming that an inherent item is inseparable from some subject or other. Rather I believe that the passage can be read as committed to the claim that a given nonsubstantial individual is inseparable from some individual substance or other.

The expression, 'cannot exist separately (adunaton chôris einai) from what it is in (tou en hôi estin)', in 1a24-25 is ambiguous between at least two claims. Under one disambiguation, the claim is that a thing cannot exist separately from what specific item the thing is in. This disambiguation precludes a nonsubstantial universal from existing separately from an individual substance. And yet, we have seen that there is good evidence that Aristotle holds that nonsubstantial universals are present in individual substances. One reaction is to assume that this disambiguation is the intended meaning of the expression and to reject that Aristotle holds that nonsubstantial universals are present in individual substances. This, for example, is the reaction of Ackrill. Another reaction is to assume that this disambiguation is the intended meaning of the expression and to look for some subject other than an individual substance as the subject from which a non- 
substantial universal is inseparable. This is, for example, the reaction of Owen. However, a third kind of reaction is to look for another disambiguation of the expression. Under one other disambiguation, for example, the claim that a thing cannot exist separately from what it is in is the claim that a thing cannot exist separately from what kind of item the thing is in.

I propose an account of inherence based on this disambiguation:

(E) $\mathrm{x}$ is present in a subject $\mathrm{y}$ just in case:

(i) $\mathrm{x}$ is in $\mathrm{y}$;

(ii) $\mathrm{x}$ is neither a physical part, nor a conceptual part, of $\mathrm{y}$;

(iii) x cannot exist separately from some thing or other of y's kind.

(E) follows the lead of several of the proposals at which we have looked. (E) follows (A) and (B) in holding that there is an ordinary sense of 'in' in the definiens and a technical sense of 'in', the notion of being present in a subject, in the definiendum. (E) also follows (A) and (B) in taking 1a24-25 to provide a necessary and sufficient condition of inherence. ${ }^{7}$ However, (E) differs from (A) and (B) in taking 1a24-25 to claim that a thing cannot exist separately from what kind of item the thing is in and not to claim that a thing cannot exist separately from what specific item the thing is in. Admittedly, if (E, iii) is what Aristotle meant by the expression 'cannot exist separately from what it is in', he could have been clearer. He might have written that an inherent item cannot exist separately from that kind of thing as what it is in, using for example the Greek toioutou en hoio $i$ estin instead of tou en hôi estin. But 1a24-25 is, as written, consistent with this disambiguation. The simple relative hos (occurring in the passage as the dative hô $i$ 'what') is often used with the sense of hoios ('of such sort', see Smyth 1920, section 2493). I have left open in (E) what might count as an item as the same kind as a given subject. But a natural suggestion is that the relevant kinds are the fourfold kinds of entities in the Categories, namely, individual and universal substances, and nonsubstantial individuals and universals. So according to this suggestion, (E) claims that, if an item is present in an individual substance, then it cannot exist separately from some individual substance or other. ${ }^{8}$

Although (E) bears some similarities to the other accounts of 1a24-25 at which we have looked, (E) uniquely meets our desiderata for any proposed reading of 1a24-25 and avoids the problems of the other proposals. It meets the desideratum that tini and tou en hô estin in 1a24-25 do not refer to two different specified referents, and so avoids the problem that (B) faces. It also meets the desideratum that all occurrences of 'in' in 2a34-b7 should have the same meaning, for (E) is consistent with holding that both nonsubstantial individuals and nonsubstantial universals are present in individual substances. So (E) avoids the problem that

7 (E) follows (D) in taking 'part' to refer to both physical and conceptual parts. I discuss the motivation for this below.

${ }^{8}$ Notice that this reading of 1a24-5 is also consistent with 2a34-b7, where Aristotle claims that 'if individual substances did not exist, then nothing else would exist'. This may well be the claim that for there to be some entity that is not an individual substance, there must be some individual substance or other. 


\section{(A) faces. ${ }^{9}$}

There are other possible alternative readings of 1a24-25. For example, it is not certain whether the passage is giving a sufficient condition for being present in a subject, a necessary condition or a necessary and sufficient condition. Erginel 2004, 194 takes 1a24-25 to be asserting merely a necessary condition for inherence, namely, the claim that $\mathrm{x}$ is in a subject only if there is a $\mathrm{y}$ such that $\mathrm{x}$ is not in $\mathrm{y}$ as a part and $\mathrm{x}$ cannot exist independently of $\mathrm{y} .{ }^{10} \mathrm{I}$ doubt that decisive reasons can be given for preferring one among various viable readings of 1a24-25. But, while it is important to exclude unattractive readings such as (A)-(D), I believe that little hinges on our choice of viable readings. For our present purposes, it is enough to show that a reading of 1a24-25 is possible that does not commit Aristotle to one position or the other on the issue of whether nonsubstantial individuals are nonrecurrent.

We have rehearsed a debate on whether or not nonsubstantial individuals are recurrent properties. However, the passages 1a24-25 and 2a34-b7 give us no reason to prefer one view over the other. So the debated interpretation of these passages is not germane to the issue. 1a24-25 can be read as making a claim that is neutral on the question of recurrence and nonrecurrence. Any nonsubstantial individual or nonsubstantial universal is present in an individual substance; and so each depends for its existence on some individual substance or other. Such a view is consistent with either the view that nonsubstantial individuals are recurrent or the view that they are nonrecurrent.

The textual evidence we have considered, then, will not answer the question whether Aristotle holds that nonsubstantial individuals are nonrecurrent. This falls short of showing that the question cannot be answered from textual considerations. But it does shift the burden of proof to one who would persist in seeking

\footnotetext{
${ }^{9}$ Moreover, (E) is not vulnerable to Erginel's criticism of (C), since (E, iii), unlike (C, iv), is not an arbitrary clause unsupported by textual evidence; rather, it is a possible disambiguation of the expression, 'cannot exist separately from what it is in', occurring in 1a24-5. Finally, (E) is not vulnerable to Wedin's criticism of (D). Recall, Wedin noted that (D) has the result that Socrates inheres in the unmoved mover, since Socrates is not a part of the unmoved mover and the situation, where Socrates exists and the unmoved does not exist, is impossible. (E) does not have this result. For, although Socrates may depend causally on the unmoved mover for his existence, and so the situation, where Socrates exists and the unmoved does not exist, is impossible, nonetheless we need not say that Socrates is present in a subject, since Socrates is not in the unmoved mover. Notice that (E), like (D), requires us to take a broad reading of the notion of a part in 1a24-5. Recall, Heinaman raises the objection to Frede that, under (D), a differentia like rational correctly fails to inhere in a species like human only if we take 'part' in 1a24-5 to refer to conceptual parts. (E) has the consequence that not only differentia but also genera correctly fail to inhere in a species only if we take 'part' in 1a24-5 to refer to conceptual parts. For a genus like animal is neither a physical part of a species like human nor does the genus have its ontological status except by standing in a tie-namely, the said of tie-to some species or other. I argued above that Heinaman's objection does not give us a good reason to reject the claim that 'part' in 1a24-5 designates both conceptual and physical parts.

${ }^{10}$ This proposal is open to neither Heinaman's objection nor Wedin's objection to (D). Like (D), it sidesteps our desideratum that tini and tou en hôi estin should not refer to two different specified referents by leaving tini unspecified.
} 
an answer from such considerations. So I assume that all evidence from the Categories is neutral on the question of recurrence. What explains this neutrality? With what project is Aristotle engaged, in writing the Categories, such that a clear answer to the question is not to be had? To answer this new question, I turn now away from local textual considerations and towards broader methodological considerations. I argue that Aristotle's concern with individuals in the Categories is one where the question of recurrence is of no immediate consequence.

\section{Methodological Considerations}

It will be helpful to distinguish between two philosophical projects concerning individuals. One project aims to provide a detailed strategy for identifying the individuals of a variety of kinds. Call this a project of individuation. Typically, such a project would yield necessary and sufficient conditions for being an individual, or at least a distinguishing mark of individuals, for each kind of individual, which would allow us to pick out the individuals among various kinds of entities. The other project aims to provide a general account of what it is to be an individual. Call this a project of characterizing individuality. Typically, such a project would yield a definition or an account of individuality that would explain what is distinctive about individuals, what is common to all individuals of various kinds, and how individuals differ from other kinds of entities. The two projects, the project of individuation and the project of characterizing individuality, may very well overlap. For example, a definition of individuality, providing a general account of what it is to be an individual, may also yield a criterion for identifying the individuals, thereby satisfying the project of individuation. Or a distinguishing mark of individuals, used to identify the individuals, may help to explain at least partly how individuals differ from other kinds of entities, thereby satisfying the project of characterizing individuality. However, the two projects are distinct. One could at least partly fulfill the success conditions of the one project without thereby satisfying the success conditions of the other project. For example, one could explain the general difference between individuals and universals without providing a criterion for identifying individual properties. In particular, one could provide a general account of what it is to be an individual, applicable to both individual substances and nonsubstantial individuals, without specifying whether nonsubstantial individuals are recurrent or nonrecurrent. I argue that it is the latter project, the project of characterizing individuality, in which Aristotle is engaged in the Categories while it is the former project, the project of individuation, to which the question of recurrence is relevant. Aristotle's intention in this work is to provide a general account of what it is to be an individual, applicable to both individual substances and nonsubstantial individuals, and does not specify whether nonsubstantial individuals are recurrent or nonrecurrent.

This goes to the heart of the lengthy debate over nonsubstantial individuals since the question of recurrent properties rests on the assumption that Aristotle is engaged, in the Categories, in the project of individuation. The debate over non- 
substantial individuals is, on its surface, a debate over whether such individuals are recurrent; but the controversy is, at a deeper and philosophically more interesting level, a debate over how Aristotle specifically goes about identifying the individuals. Recall that, in our initial discussion of the philosophical issue, we compared two competing pictures of how one might identify an individual. On one picture, nonsubstantial individuals are individuated by individual substances. What makes Callias' paleness an individual, on this view, is that it is his alone. The project of individuating the individuals, under this picture, is one of first identifying the individual substances and the various categories of nonsubstances such as qualities and quantities. The nonsubstantial individuals will then be identified as instances of nonsubstantial categories individuated by the individual substances in which they inhere. On this picture, the nonsubstantial individuals are necessarily nonrecurrent. This then is the picture that is presumably driving those who, following Ackrill, defend the view that nonsubstantial individuals are nonrecurrent.

On a rival picture, the project of individuating individuals is the project of identifying the least general items, items which are classifiable but are not themselves classifying. Such items would not be instances of universals but rather they would be maximally determinate species of determinable genera. ${ }^{11}$ In the case of substances, the least general items are the individual substances and these happen to be nonrecurrent. But it is not obvious that, in the case of nonsubstance categories such as quality and quantity, the least general items will be nonrecurrent. These may be recurrent or nonrecurrent. Indeed, there may not be a uniform answer for the question whether nonsubstantial individuals are recurrent or nonrecurrent, and it may even be that only a case by case study will decide the issue. This is the picture that is perhaps driving those who, following Owen, defend the view that nonsubstantial individuals are not necessarily nonrecurrent. ${ }^{12}$

11 The terminology of the determinable-determinate distinction stems from scholastic discussion of the definition of a given species. A genus is the determinable part of the essence or pars determinabilis essentiae and a differentia is a determining part of the essence or pars determinans essentiae. For some of the history of the topic, see Prior 1949. The modern determinable-determinate distinction was initially drawn by Johnson 1921, 173-185. Although Owen and others who hold that nonsubstantial individuals are recurrent describe nonsubstantial individuals as maximally determinate items, it is controversial whether maximally determinate items are recurrent. Johnson 1921, for example, seems to view maximally determinate items as recurrent items, the traditional infirmae species, such as man. Funkhouser 2006, on the other hand, holds that maximally determinate items are nonrecurrent tropes.

12 This is perhaps the picture with which Moravscik 1967, 89 is working when he writes: 'a survey of difficulties encountered by the interpretations of Ackrill and Owen leads us to the conclusion that neither could all the categories other than substance contain non-recurrent particulars (for example, the category of relation), nor could one regard all of these as containing only universals (for example, the category of place)'. There is much to agree with here, even if we do not endorse Moravcsik's specific examples of nonrecurrent nonsubstantial individuals and recurrent nonsubstantial individuals. The project of identifying the individuals, in the sense which Moravcsik is concerned, is complex and arguably nonuniform. The picture I have just described at least does not exclude the possibility that some nonsubstantial individuals are both nonclassifying and nonrecurrent. So it is 
Unfortunately, I doubt that anything in the Categories will tell us which picture is Aristotle's own view of the project of individuating individuals. For Aristotle is not engaged with either version of this project in this work. The one picture, the project of individuating nonsubstantial individuals by the individuals substances in which they inhere, would be partially satisfied by the methodology of the Categories, since that project only requires that we identify the individual substances and the categories of nonsubstances, and the Categories identifies the various categories of nonsubstances. But Aristotle does not explicate in the Categories how to go about individuating individual substances. It is controversial whether Aristotle ever advocates a principle of individuation for individual substances. And, among those who hold that Aristotle has a principle of individuation for individual substances, it is controversial whether it involves form or matter. What should not be controversial, however, is that Aristotle does not explain the individuation of individual substances in the Categories. For both candidates for a principle of individuation, form and matter, require appeal to Aristotle's hylomorphic analysis of substances; and it is uncontroversial that hylomorphism plays little or no role in the Categories. So regardless of one's position on the debated interpretation of Aristotle's principle of individuation for individual substances, the project of individuating individual substances by means of one of the standard interpretation of Aristotle's principle of individuation is not the project in which Aristotle is engaged in the Categories. Now, the fact that Aristotle does not offer a hylomorphic analysis of substances in the Categories fails to show decisively that he does not aim in the Categories to explain how to individuate substances. But, if Aristotle does individuate substances in the Categories, then he must do so by appeal to some alternative method of individuation not discussed in the secondary literature on Aristotle's principle of individuation. So the onus is on one who would find a project of individuation in the Categories to provide this hitherto unrecognized alternative. Certainly, none of the explicit marks of substance, discussed in Categories 5, provides a means of individuating substances. These marks - substances do not have contraries, do not admit of degree, remain numerically one while receiving contraries-are not ways of distinguishing one substance from another; they are typically ways of distinguishing substances from nonsubstances. ${ }^{13}$

The other picture, the project of identifying the least general items, is not the project in which Aristotle is engaged in the Categories, either. Consider a candidate for a nonsubstantial individual that is nonetheless recurrent-Owen's vink, say. Vink, recall, is a shade of pink not intelligibly divisible into finer-grained

with this picture that a nonuniform account of individuals is in the offing.

${ }^{13}$ For the view that Aristotle's principle of individuation for individual substances is the individual's form, see, e.g., Sellars 1957 and Frede 1987. Of course, Frede holds that Aristotle has a principle of individuation for individual substances but does not individuate nonsubstantial individuals by individual substances. For the view that Aristotle's principle of individuation for individual substances is the individual's matter, see, e.g., Lloyd 1970. For the view that Aristotle does not address the issue of individuation at all, see Charlton 1972. 
shades. On what grounds is vink not further divisible? What criteria would allow us to identify a given colour as a determinate, but not further determinable, kind? A plausible candidate for colours might involve our colour recognition abilities. One might claim that we can consistently distinguish vink from other shades of pink, but be unable consistently to distinguish finer-grained shades. This would be a reasonable criterion for identifying the least general colours. But there is no such account in the Categories, or any other account that could be taken to be a criterion for identifying the least general colours. And generally, Aristotle in the Categories does not provide criteria for identifying the least general items for any nonsubstance. Aristotle discusses the various ways in which different nonsubstantial categories differ - what is, for example, distinctive of quantities as opposed to qualities. And he discusses broad subdivisions within a category - for example, how discrete quantities differ from continuous quantities. But he does not even discuss in much detail specific cases of nonsubstances - how, for example, colours differ from tastes or other sensible qualities. And we fail to see any discussion of the distinctive individuation conditions for specific cases such as colour or taste. So Aristotle does not address the question, what criteria would allow us to identify, as the least general items, the nonsubstantial individuals? Neither version of the project of individuating the individuals, then, is to be found in the Categories.

What Aristotle does provide in the Categories are characterizations of what it is to be an individual. These characterizations emphasize contrasts between individuals and universals. I give just one example. Aristotle characterizes individuals, at 1b6-7 and 3b12, as being 'indivisible and numerically one' (ta atoma kai hen aristhmôi). In characterizing individuals as numerically one, he contrasts individuals with universals, characterized elsewhere as unified by species or genus. At Metaphysics v 6 and elsewhere, Aristotle characterizes the distinction between individuals and universals by distinguishing between two kinds of unity: numerical, on the one hand, and specific or generic, on the other. So in speaking of an individual as one in number in the Categories, it is likely that Aristotle is contrasting individuals with universals in terms of their different modes of unity. In characterizing individuals as indivisible, he contrasts individuals with universals, characterized elsewhere as divisible. Aristotle often talks of genera as if they were aggregates divided by species. For example, he describes governments as being divided into monarchies and aristocracies and such in Politics iv 2.1289a26; he speaks of dividing a genus into species, for example, at Prior Analytics i $31.46 \mathrm{a} 38$ and of a genus being divided by differentiae, for example, at Metaphysics vii 12.1038a9. So Aristotle holds that a genus can sometimes be treated as a collection of the various species falling under that genus. A species likewise can be split into subspecies and so on. Individuals provide the limit case, as items which cannot be further divided into parts of the same kind. ${ }^{14}$

${ }^{14}$ Notice that the characterization of individuals as indivisible and numerically one is neutral on the question of recurrence. On the view that nonsubstantial individuals are nonrecurrent, nonsubstantial universals are divided into properties distinguished by being possessed by different substances. 
To conclude, the issues with which Aristotle is concerned in the Categories are tangential to the question whether any individual is recurrent or nonrecurrent. Aristotle's aim in this work is not to explain how to identify the individuals but rather to characterize what it is to be an individual. The latter project may be undertaken without thereby undertaking the former project. And indeed, Aristotle's account of individuals in the Categories tells us next to nothing as to how the individuals are to be identified. In particular, the account is neutral with respect to the question whether nonsubstantial individuals are recurrent or nonrecurrent. For this reason, debates over local issues of textual interpretation in the Categories are unlikely to yield results. Aristotle's claim that inherent items are inseparable from that in which they are present does not commit him to a position on recurrence. If there is a decisive answer to be had, on the question of Aristotle's view of the individuation of nonsubstances, it will likely come from considerations from elsewhere in Aristotle's metaphysics and philosophy of science. ${ }^{15}$ There seems to be nothing in the Categories that will answer the question. ${ }^{16}$ But

Clearly these properties are indivisible in the relevant sense, for they cannot be further divided into properties individuated by distinct individual substances. On the view that nonsubstantial individuals are recurrent, nonsubstantial universals are divided into individual properties that may be shared by two individual substances. Although recurrent, these individuals are not divisible into two distinct properties, the one possessed by me and the other possessed by you. For these properties are not, on this view, distinct. Finally, Devereux 1992 has drawn on the characterization of individuals as numerically one so to argue that nonsubstantial individuals are nonrecurrent because they are demonstrable. Devereux asserts that being indivisible and numerically one are jointly sufficient for being a this; all thises are nonrecurrent; and so nonsubstantial individuals are nonrecurrent. The premise that being indivisible and numerically one are jointly sufficient for being a this is controversial; for discussion, see Sharma 1997 and Devereux 1998. However the debated premise is not obviously germane to the issue of whether nonsubstantial individuals are recurrent. For it is not clear that being nonrecurrent is a necessary condition for being demonstrable. Arguably, one could demonstrate a recurrent nonsubstantial individual. At any rate, it is not obvious that one could not demonstrate a least general property.

${ }^{15}$ I am not optimistic that, even here, textual considerations will prove fruitful. One relevant passage is 1089b24-28: 'In the categories other than substance there is another matter to give pause, viz. how can there be many? For since they are not separable, qualities and quantities are many only because their substrate becomes and is many. Yet there ought to be a matter for each category; only it cannot be separable from substances.' At first blush, this passage might lend some support of the view that nonsubstantial individuals are individuated by individual substances and so are nonrecurrent. There are reasons for caution, however. The passage occurs in a list of problems for Platonism and so perhaps cannot bear much weight as evidence of Aristotle's considered view. Aristotle is clearly canvassing various reasons for how nonsubstances may be many; it is not clear that Aristotle is here endorsing any reason. Moreover, there is room for considerable disagreement in extracting Aristotle's actual views from this passage. Annas 1974, for example, sees the passage as canvassing an alternative principle of individuation in terms of matter. Finally, it is not entirely clear that Aristothe is concerned with individuation at all: his talk of nonsubstances being many may refer not to the question how there can be several nonsubstantial individuals but rather the question of how there can be nonsubstantial universals.

${ }^{16}$ My claim that the Categories lacks an answer to the question whether Aristotle allows for nonrecurrent properties is anticipated by a few authors. Matthen 1978, 240-241 holds that the goal of the Categories is doxographical and not theoretical. Since the Categories, for Matthen, is concerned not with providing an ontology but with setting out the phenomenological data that an ontology must 
moreover, were we able to answer this question, it would shed little light on Aristotle's Categories. For none of the issues involving individuals with which Aristotle himself is explicitly concerned in that work hinges on the question. As such, the issue of recurrence is otiose for our understanding of the Categories, a quagmire which never held promise of more than slim interpretative rewards. ${ }^{17}$

Department of Philosophy

University of Alberta

Edmonton, Canada T6G 2E7

\section{LABELLED SENTENCES}

(A) $\mathrm{x}$ is present in $\mathrm{y}$ just in case:

(i) $x$ is in $y$

(ii) $\mathrm{x}$ is not a part of $\mathrm{y}$

(iii) $\mathrm{x}$ cannot exist independently from $\mathrm{y}$.

(B) $\mathrm{x}$ is present in $\mathrm{y}$ just in case there is a $\mathrm{z}$ such that:

(i) $\mathrm{x}$ is in $\mathrm{y}$

(ii) $x$ is not a part of $y$

(iii) $\mathrm{x}$ cannot exist apart from $\mathrm{z}$.

(C) $\mathrm{x}$ is in something, $\mathrm{z}$, as its subject just in case there is a subject $\mathrm{y}$ such that:

(i) $x$ is in $y$

(ii) $\mathrm{x}$ is not a part of $\mathrm{y}$

(iii) $\mathrm{x}$ cannot exist apart from $\mathrm{y}$

(iv) if $\mathrm{y}=\mathrm{z}$ then either $\mathrm{x}$ is an individual iff $\mathrm{y}$ is an individual; or

$\mathrm{x}$ is a universal iff $\mathrm{y}$ is a universal.

(D) $\mathrm{x}$ is present in a subject if there is a $\mathrm{z}$ such that:

(i) $\mathrm{x}$ is not a part of $\mathrm{z}$

(ii) $\mathrm{x}$ cannot exist independently from $\mathrm{z}$.

explain, it lacks the ontological resources to address the issue of recurrence. And Sharma 1997, 314 asserts that no answer to the question whether Aristotle allows for nonrecurrent properties will be found in textual considerations, since in 'the Categories, Aristotle is thinking of first-order accidents almost entirely relative to the natural-language expressions that designate them; he is not yet discussing any philosophical problem relative to which a specific account the nature of those accidents becomes crucial'. I do not share these authors's view that the aim of the Categories is mere doxography or little more than a classification based on ordinary language usage. I have argued in my 2008 that Aristotle's purpose generally in the Categories is to provide a principled ontology. Although linguistic evidence provides a range of predicables, the dominant goal of the work is to employ the present in and said of ties to relate these predicables of various kinds to individual substances. So the Categories does not merely classify but also provides a rationale for the classification of entities. Nonsubstantiality and universality are the central concerns of such a project, not individuality. But part of this project is to bring out the contrast and interrelationships obtaining between individuals and universals. These characterizations of individuals do not provide guidance as to how to identify individuals, and I doubt that Aristotle sees philosophy as well suited for this task.

${ }^{17}$ Thanks to Sean Kelsey, Gavin Lawrence, Calvin Normore, Ronald Polansky, and the audiences of papers given at the American Philosophical Association Eastern Division Meeting and at the University of Illinois, Urbana-Champaign. 
(E) $\mathrm{x}$ is present in a subject $\mathrm{y}$ just in case:

(i) $\mathrm{x}$ is in $\mathrm{y}$;

(ii) $\mathrm{x}$ is neither a physical part, nor a conceptual part, of $\mathrm{y}$;

(iii) $\mathrm{x}$ cannot exist independently of some thing or other of y's kind.

(A1) If $\mathrm{x}$ cannot exist independently from an individual subject, then $\mathrm{x}$ is nonrecurrent.

(A2) Only nonrecurrent properties can be present in individual substances.

\section{BIBLIOGRAPHY}

Ackrill, J.L. 1963. Aristotle's Categories and De Interpretatione. Translated with Notes and Glossary. Oxford: Clarendon Press.

Allen, R.E. 1969. 'Individual Properties in Aristotle's Categories' Phronesis 14: 31-39.

Annas, J. 1974. 'Individuals in Aristotle's Categories: Two Queries' Phronesis 19: 146-152.

Anscombe, G.E.L. 1963. 'Aristotle' 1-63 in Three Philosophers. Oxford: Oxford University Press.

Armstrong, D. 1989. Universals: An Opinionated Introduction. Boulder, CO: Westview Press.

Burnyeat, M. et al. edd. 1979. Notes on Book Zeta of Aristotle's Metaphysics. Oxford Study Aids in Philosophy.

Cook Wilson, J. 1926. Statement and Inference, with Other Philosophical Papers. Oxford: Clarendon Press.

Corkum, P. 2008. 'Aristotle on Ontological Dependence' Phronesis 53: 65-92.

Dancy, R. 1975. 'On Some of Aristotle's First Thoughts About Substances' Philosophical Review 84: 338-373.

Devereux, D. 1992. 'Inherence and Primary Substance in Aristotle's Categories' Ancient Philosophy 12: 113-131.

Devereux, D. 1998. 'Aristotle's Categories 3b 10-21: A Reply to Sharma' Ancient Philosophy 18: 341-352.

Duerlinger, J. 1970. 'Predication and Inherence in Aristotle's Categories' Phronesis 15: 179-203.

Erginel, M. 2004. 'Non-Substantial Individuals in Aristotle's Categories' Oxford Studies in Ancient Philosophy 26: 185-212.

Fine, K. 1985. Reasoning with Arbitrary Objects. Oxford: Blackwell.

Frede, M. 1987. 'Individuals in Aristotle' 49-71 in Essays in Ancient Philosophy. Minneapolis: University of Minnesota Press.

Funkhouser, E. 2006. 'The Determinable-Determinate Relation' Nous 40: 548-569.

Furth, M. 1988. Substance, Form and Psyche: An Aristotelian Metaphysics. Cambridge: Cambridge University Press.

Gill, M.L. 1984. 'Aristotle on the Individuation of Changes' Ancient Philosophy 4: 9-22.

Gill, M.L. 1989. Aristotle on Substance: The Paradox of Unity. Princeton: Princeton University Press.

Grice, H.P. 1988. 'Aristotle on the Multiplicity of Being' Pacific Philosophical Quarterly 69: 175200.

Heinaman, R. 1981. 'Nonsubstantial Individuals in the Categories' Phronesis 26: 295-307.

Hetherinton, S.C. 1984. 'A Note on Inherence' Ancient Philosophy 4: 218-223.

Johnson, W.E. 1921. Logic. vol. 1. Cambridge: Cambridge University Press.

Jones, B. 1972. 'Individuals in Aristotle's Categories' Phronesis 17: 104-123.

Jones, B. 1975. 'An Introduction to the First Five Chapters of Aristotle's Categories' Phronesis 20: 146-172.

Matthen, M. 1978. 'The Categories and Aristotle's Ontology' Dialogue 17: 228-243.

Matthews, G. 1989. 'The Enigma of Categories 1a20ff. and Why It Matters' Apeiron 22: 91-104.

Matthews, G. 1991. 'Container Metaphysics According to Aristotle's Greek Commentators' Canadian Journal of Philosophy supp. vol. 17: 7-23.

Matthews, G. and S.M. Cohen. 1968. 'The One and the Many' Review of Metaphysics 21: 630-655. 
Mertz, D. 1996. Moderate Realism and its Logic. New Haven: Yale University Press.

Moravcsik, J.M.E. 1967. 'Aristotle on Predication' Philosophical Review 76: 80-96.

Owen, G.E.L. 1965. 'Inherence' Phronesis 10: 97-105.

Prior, A. 1949. 'Determinables, Determinates and Determinants' Mind 58: 1-20.

Rohr, M. 1978. 'Aristotle on the Transitivity of Being Said Of' Journal of the History of Philosophy 16: $379-385$.

Sharma, R. 1997. 'A New Defense of Tropes? On Categories 3b10-18' Ancient Philosophy 17: 309316.

Smyth, H. 1920. Greek Grammar. Cambridge: Harvard University Press.

Strawson, P. 1959. Individuals. An Essay in Descriptive Metaphysics. New York: Routledge.

Wedin, M. 1993. 'Nonsubstantial Individuals' Phronesis 38: 137-165.

Wedin, M. 2000. Aristotle's Theory of Substance. New York: Oxford.

Wheeler, M. 1999. 'The Possibility of Recurrent Individuals in Aristotle's Organon' Gregorianum 80: 539-551.

Williams, D.C. 1953. 'The Elements of Being' Review of Metaphysics 7: 3-18, 171-192. 